\title{
Three Different Benign Breast Lesions of Undetermined Risk in the Same Patient
}

\author{
Coronado $\mathrm{P}^{1}$, Maiz C ${ }^{2}$, Vargas $\mathrm{C}^{2}$, Razmilic $\mathrm{D}^{3}$, Oddó $\mathrm{D}^{4}$, Villarroel MA ${ }^{4}$, Sánchez C ${ }^{5}$, Merino $\mathrm{T}^{5}$ and Camus $\mathrm{M}^{2}$ \\ ${ }^{1}$ Division of Obstetrics and Gynecology, Pontificia Universidad Católica de Chile, Chile
}

${ }^{2}$ Department of Surgical Oncology, Pontificia Universidad Católica de Chile, Chile

${ }^{3}$ Department of Radiology, Pontificia Universidad Católica de Chile, Chile

${ }^{4}$ Department of Anatomical Pathology, Pontificia Universidad Católica de Chile, Chile

${ }^{5}$ Department of Hematology-Oncology, Pontificia Universidad Católica de Chile, Chile

Submission: August 08, 2017; Published: August 22, 2018

*Corresponding author: Mauricio Camus A, Department of Surgical Oncology, Pontificia Universidad Católica de Chile, Marcoleta 367, Santiago, Chile, Tel: (562) 23543720; Email: mcamus@med.puc.cl

\begin{abstract}
We present the case of a 37-years old women with three rare benign lesions of undetermined risk at the same time: a fibromatosis, phyllodes and intraductal papilloma, who was treated by a partial mastectomy. We focus the discussion on fibromatosis, since the other two entities have been previously discussed by our group in other publications.

Keywords: Breast fibromatosis; Phyllodes; Intraductal papilloma

Abbreviations: UOQ: Upper-Outer Quadrant; UQU: Upper Quadrants Union; IQU: Inner Quadrants Union; NSAIDs: Non-Steroidal AntiInflammatory Drugs
\end{abstract}

\section{Introduction}

Breast fibromatosis is a rare benign tumor, with uncertain prognosis and management. The objective of this work is to present the case of a patient who had three uncommon benign lesions of the breast and to discuss their management, focusing on the fibromatosis, since the other two entities have been previously discussed by our group in other publications [1,2].

\section{Case Report}

We present the case of a healthy 37 years-old women, with self-detected right breast nodule with 6-months evolution, that was progressively growing and sensitive at touch, associated with erythema and pruritus. She had a familial history of two cousins with breast cancer. At physical exam, there was a hard tumor of approximately $60 \times 50 \times 30 \mathrm{~mm}$ at the upper quadrants union (UQU) of the right breast and another $20 \mathrm{~mm}$ nodule, difficult to separate from the bigger tumor, toward the upperouter quadrant (UOQ). She was studied with a contrasted mammography that showed a $45 \mathrm{~mm}$ round-shaped nodule with spiculated edges and early enhancement with contrast, at the UQU (BIRADS-5) and a second $22 \mathrm{~mm}$ well delimited and moderate enhancing nodule at the upper outer quadrant
(UOQ) of the right breast (Figure 1) without invasive-suspected lesions at the left breast. The breast ultrasound demonstrated a $42 \mathrm{~mm}$ heterogeneous, lobulated mass with imprecise limits and hypoechoic central portion associated with microcalcifications at the UQU of the right breast (Figure 2), a solid oval-shaped well delimited and vascularized $15 \mathrm{~mm}$ nodule at the UOQ (Figure 3). There was also a $10 \mathrm{~mm}$ solid-cystic lesion at the inner-quadrants union (IQU) of the left breast (Figure 4). A core biopsy of the two right breast masses was then performed, demonstrating a biphasic fibro-epithelial lesion. The patient underwent a partial bilateral mastectomy of the three lesions, two of them previously marked under ultrasound guidance. The definitive biopsy demonstrated that the lesion of the UQU of the right breast - hour 12, corresponded to a fibromatosis (Figures 5 \& 6), and that the other lesion of the UOQ of the right breast was a phyllodes tumor with signs of benignity (Figure 7). In the left breast, an intraductal papilloma was found (Figure 8). The case was discussed at the Oncologic Committee, deciding to follow-up the patient at 6 months with breast ultrasound and contrasted mammography and to offer chronic treatment with celecoxib. 


\section{Juniper Online Journal of Case Studies}

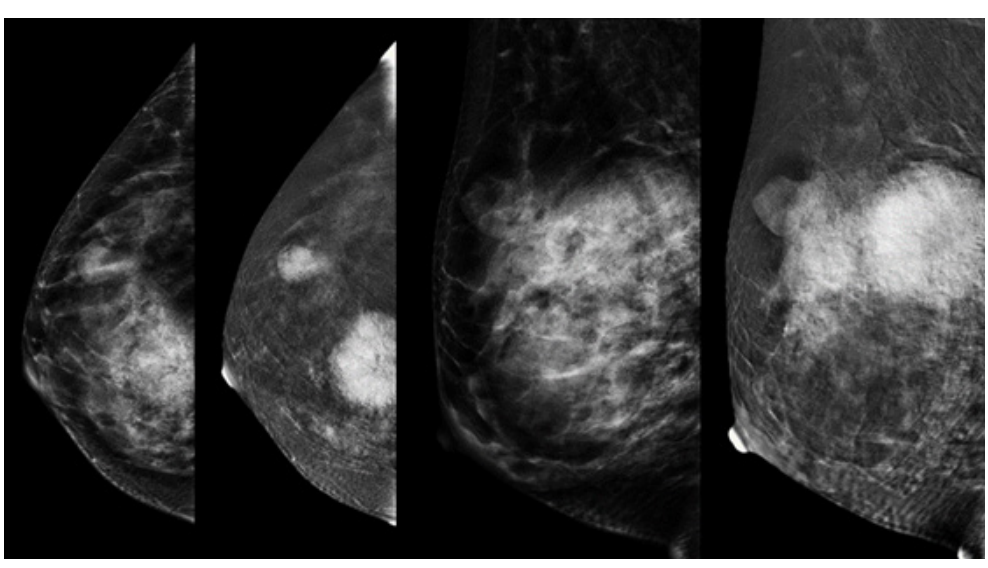

Figure 1: Right contrasted mammography showing a dense breast, with an ill-defined big round-shaped mass measuring $45 \mathrm{~mm}$ in greatest diameter at the UQU and a well-defined $22 \mathrm{~mm}$ nodule at the UOQ. Both lesions have an intense, discretely heterogeneous, enhancement after the contrast use. A) Mediolateral-oblique and B) Cephalo-caudal projections.

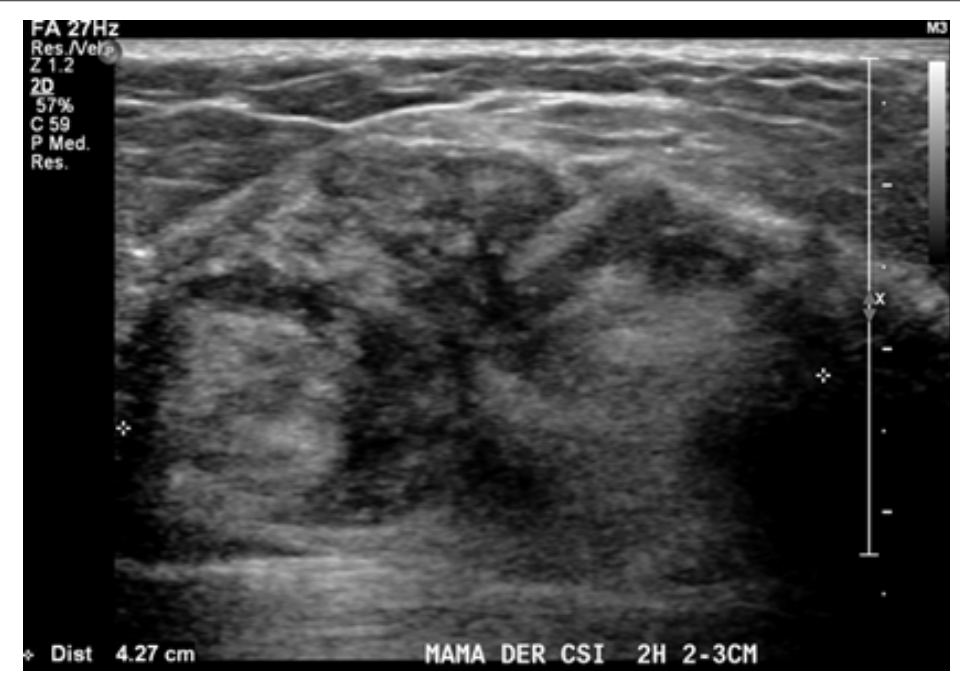

Figure 2: Right breast ultrasound showing a heterogeneous $42 \mathrm{~mm}$ ill-defined, lobulated mass that corresponded to the palpable lesion described at mammography.

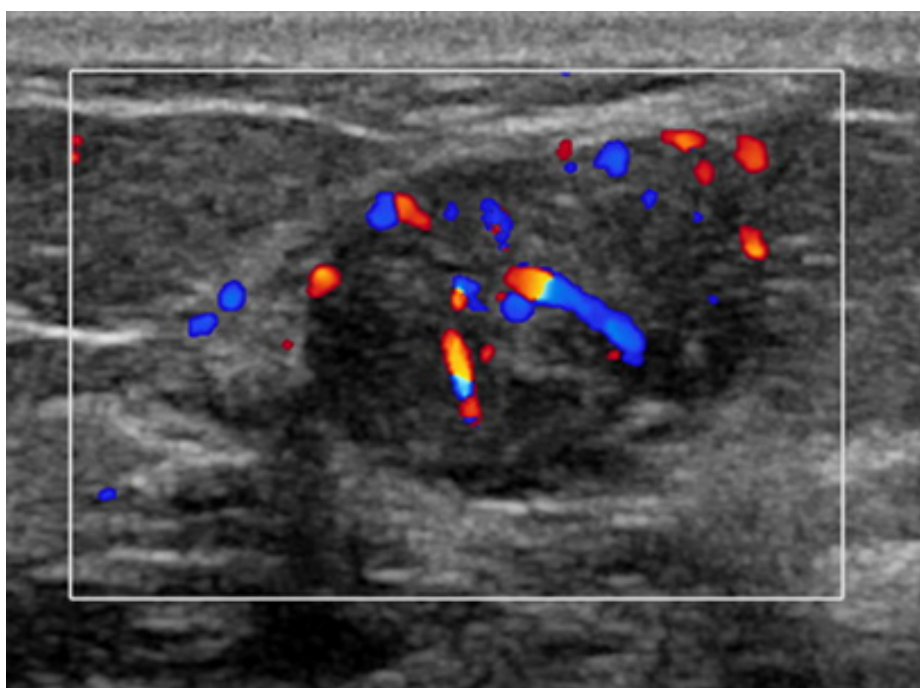

Figure 3: Right breast ultrasound showing a $19 \mathrm{~mm}$, solid, slightly lobed, well-defined and vascularized nodule at the UOQ. 


\section{Juniper Online Journal of Case Studies}

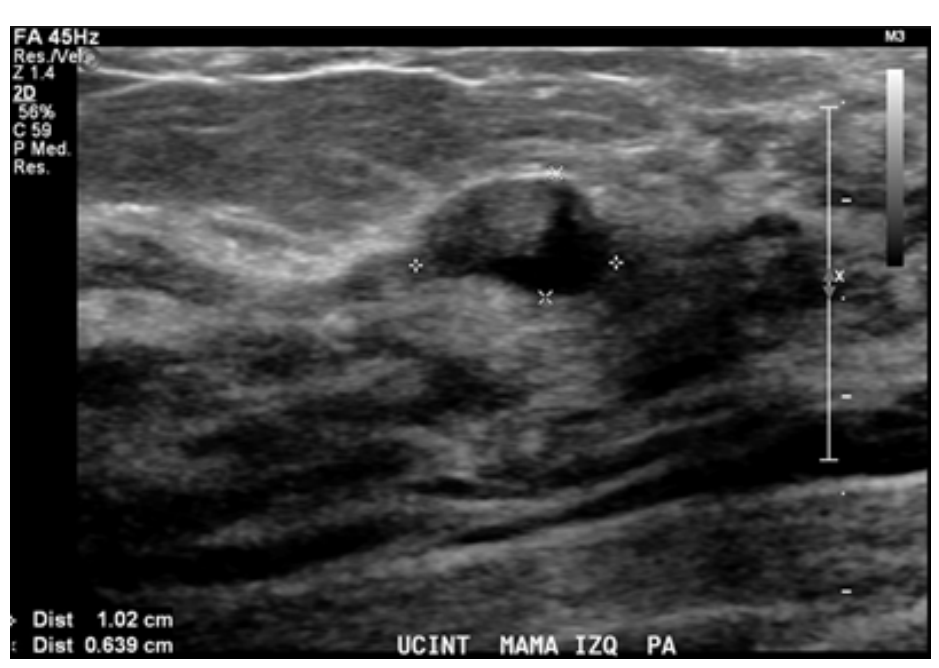

Figure 4: Right breast ultrasound showing Lactiferous duct with a periareolar focal dilatation located at the IQU of the left breast with a 4,7 $\mathrm{mm}$ nodular echogenic lesion inside with the appearance of an intraductal papilloma.

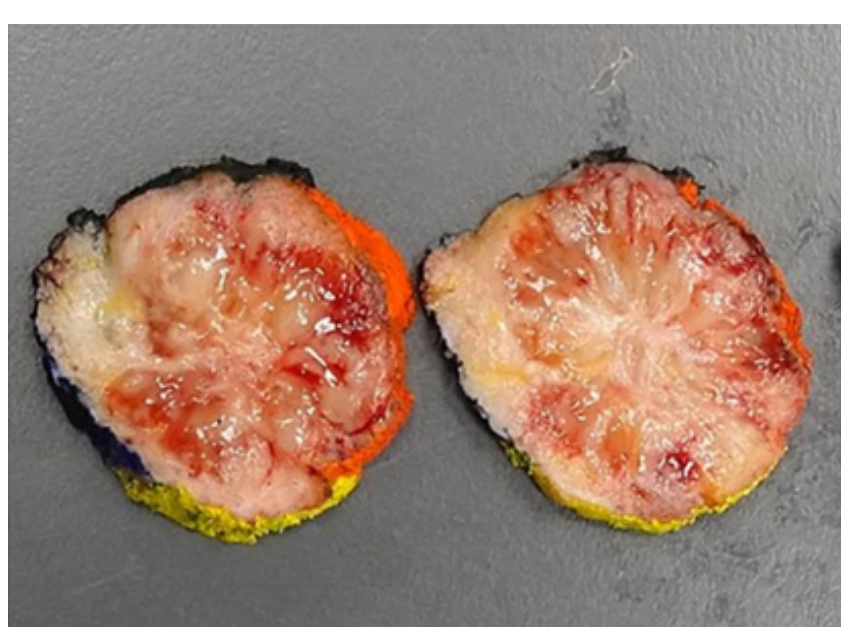

Figure 5: Fibromatosis macroscopy. Stellate tumor lesion of $4.5 \times 4.2 \times 4.2 \mathrm{~cm}$

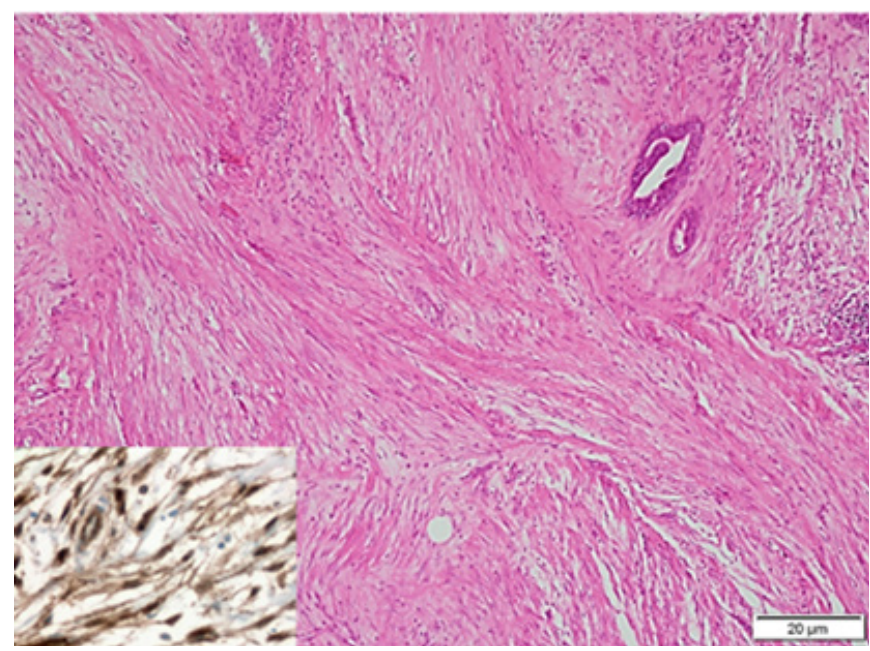

Figure 6: Fibromatosis microscopic typical appearance (haematoxylin - eosin X100, original magnification). In the lower box, positivity for beta-catenin is observed (immunohistochemistry X 400, original increase). 


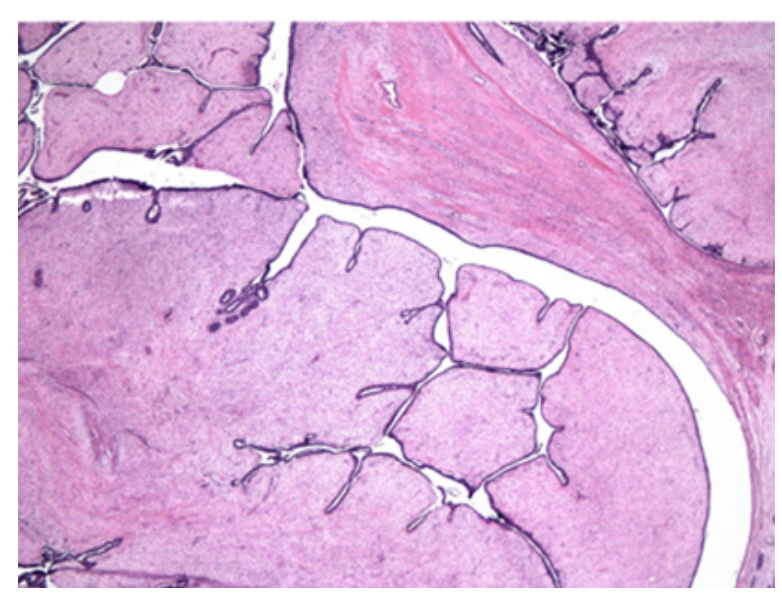

Figure 7: Phyllodes tumor (haematoxylin - eosin X100, original magnification).

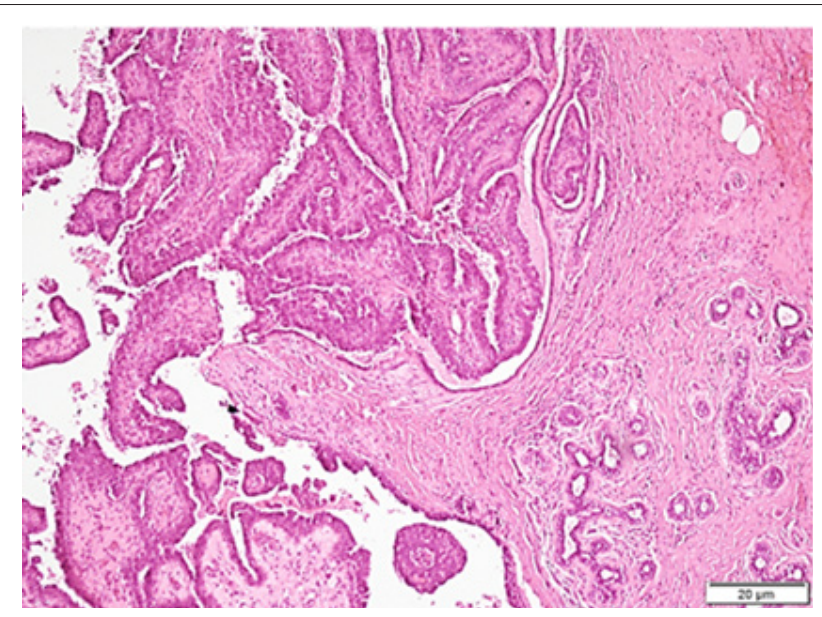

Figure 8: Intraductal papilloma (haematoxylin - eosin X100, original magnification).

\section{Discussion}

\section{Fibromatosis}

Fibromatosis is a monoclonal fibroblastic proliferation derived from deep soft tissues. It is characterized by infiltrative growth and local recurrence tendency, without metastasizing capacity, although in $10 \%$ of the cases, it could be multifocal [3]. According to the Soft Tissue Tumors classification of the World Health Organization, it corresponds to an intermediate - locally aggressive lesion [4]. Reported incidence is 5-6 cases per million people, corresponding to less than $3 \%$ of all soft tissue tumors. It presents mainly in young women, with a peak incidence at 30-40 years, but could appear at any age [5]. Most frequent localizations are the trunk, abdomen and limbs, with the breast being a rare place of appearance, corresponding to $0,2 \%$ of all breast tumors. The etiology is unknown, but it has been observed that in 85$90 \%$ of cases there is a mutation at the beta-catenin gene, which related with proliferation and cell survival [6]. Gardner's syndrome has been described as a risk factor in the context of familial adenomatous polyposis, present in $10-20 \%$ of patients, as well as trauma and surgery history. In a retrospective study, up to $25 \%$ of the patients had history of breast cancer [7], and it has also been described associated with breast implants [8], which could be explained by a molecular connection between scarring and tissue fibroproliferative alterations [3]. By other side, pregnancy, probably due to exposure to high amounts of estrogen, has been associated with the appearance of this tumor.

Clinically it presents as a firm, painless or slightly painful mass, sometimes with retraction of the skin or nipple, without discharge or palpable axillary adenopathies. In mammography, it is usually confused with breast cancer due to its irregular shape with spiculated margins, just as in ultrasound, where it is seen as a poorly defined hypoechoic lesion with posterior acoustic shadow and an echogenic ring [9]. The diagnosis is confirmed by core biopsy of the lesion.

Unfortunately, fibromatosis has an unpredictable course and there are no prognostic factors that help us determine which treatment is best suited for each patient. The current recommendation as first line treatment is expectant and symptomatic management, especially in asymptomatic patients, with no risky tumors, and those who are unresectable. Observational studies have shown that approximately $50 \%$ of the patients may progress in 5 years follow-up $[1,10,11]$ and that 20-30\% have spontaneous tumor resolution [12]. 


\section{Juniper Online Journal of Case Studies}

Pregnancy is not considered an absolute indication of surgery. Although $40-50 \%$ of these tumors progress during this period, it has not been associated with adverse obstetric outcomes. When planning pregnancy in a patient with breast fibromatosis, it is recommended to previously observe the tumor behavior for two years $[3,13]$.

Regarding surgical management, it is recommended to resect the tumor with negative margins, although it has no impact in recurrence $[3,14]$. Factors associated with recurrence include tumor location (more frequent in the abdominal wall) and the mutation type of the beta-catenin gene $[3,15]$. It has been described that recurrence 15 months after surgery would be approximately 29\% [7]. There are multiple options for medical management. Complete pathological response has been observed with non-steroidal anti-inflammatory drugs (meloxicam, indomethacin and sulindac), however nor the duration of the treatment or the effect are well described [1620]. Other option includes using tamoxifen associated or not to NSAIDs. Chemotherapy is reserved for unresectable, fastgrowing or irresponsive to hormonal treatment tumors [21,22]. Radiotherapy can be used as primary management for the tumor, with $70-80 \%$ reported long-term local control, as well as an adjuvant treatment, when there are positive margins, the latter being a controversial indication [5,23].

\section{Phyllodes}

Phyllodes tumors of the breast are rare fibro-epithelial lesions, corresponding to less than $1 \%$ of breast neoplasms. According to the degree of stromal hyperplasia and atypia, the World Health Organization (WHO) categorizes phyllodes tumors into benign, borderline and malignant tumors, however, there is no consensus defining the appropriate surgical margins that ensure a reduction of the risk of recurrence [3].

\section{Intraductal papilloma}

Papillary breast lesions are characterized by growing inside the galactophorous ducts and represents a heterogeneous pathology. They are rare, constituting less than $10 \%$ of benign breast lesions and less than $1 \%$ of malignant neoplasms of the breast. The WHO classification includes 4 entities within the section on intraductal papillary lesions: intraductal papilloma, intraductal papillary carcinoma, encapsulated carcinoma and solid papillary carcinoma [24]. Its management is controversial, although there is consensus that papillomas with atypical characteristics at pathology require surgical excision, because they have a high rate of coexisting carcinoma. There is no agreement regarding the optimal treatment of papillomas without atypia [2].

\section{Informed consent}

The patient gave her informed consent to publish the case.

\section{References}

1. Vial MC, Maiz C, Jarry C, Oddó D, Camus M (2017) Concomitant Phyllodes Tumour and Hamartoma of the Breast. Int J Radiol Radiat Ther 3(3): 00065.
2. Pulgar D, Jans J, Petric M, Oddo D, Navarro M, et al. (2014) Breast papillary lesions. An analysis of 70 cases. Ecancermedicalscience 8: 461.

3. Kasper B, Baumgarten C, Garcia J, Bonvalot S, Haas R, et al. (2017) An update on the management of sporadic desmoid-type fibromatosis: a European Consensus initiative between Sarcoma PAtients EuroNet (SPAEN) and european Organization for Research and Treatment of Cancer (EORTC)/Soft Tissue and Bone Sarcoma Group (STBSG). Ann Oncol 28(10): 2399-2408.

4. Fletcher CDM, Bridge JA, Hogendoorn P, Mertens F (2013) WHO Classification of Tumours of Soft Tissue and Bone. (4 $4^{\text {th }}$ edn), 5(5).

5. Micke O, Seegenschmiedt MH, German Cooperative Group on Radiother- apy for Benign Diseases (2005) Radiation therapy for aggressive fibromatosis (desmoid tumors): Results of a national Patterns of Care Study. Int J Radiat Oncol Biol Phys 61(3): 882-891.

6. Erguvan-Dogan B, Dempsey PJ, Ayyar G, Gilcrease MZ (2005) Primary desmoid tumor (extraabdominal fi bromatosis) of the breast. AJR Am J Roentgenol 185(2): 488-489.

7. Neuman HB, Brogi E, Ebrahim A, Brennan MF, Van Zee KJ (2008) Desmoid tumors (fibromatoses) of the breast: a 25-year experience. Ann Surg Oncol 15(1): 274-280.

8. Seo YN, Park YM, Yoon HK, Lee SJ, Choo HJ, et al. (2015) Breast fibromatosis associated with breast implants. Jpn J Radiol 33(9): 591597.

9. Ha K, DeLeon P, Hamilton R (2013) Breast fibromatosis mimicking breast carcinoma. Proc (Bayl Univ Med Cent) 26(1): 22-24.

10. Briand S, Barbier O, Biau D, Bertrand-Vasseur A, Larousserie Fet al. (2014) Wait-and-see policy as a first-line management for extraabdominal desmoid tumors. J Bone Joint Surg Am 96(8): 631-638.

11. Fiore M, Rimareix F, Mariani L, Domont J, Collini P, et al. (2009) Desmoid-typefibromatosis: a front-line conservative approach to select patients for surgical treatment. Ann Surg Oncol 16(9): 25872593.

12. Colombo C, Miceli R, Le Péchoux, Palassini E, Honoré, et al. (2015) Sporadic extra abdominal wall desmoid-type fibromatosis: surgical resection can be safely limited to a minority of patients. Eur J Cancer 51(2): 186-192.

13. Fiore M, Coppola S, Cannell AJ, Colombo C, Bertagnolli MM, et al. (2014) Desmoid-type fibromatosis and pregnancy: a multi-institutional analysis of recurrence and obstetric risk. Ann Surg 259(5): 973-978.

14. Salas S, Dufresne A, Bui B, Blay JY, Terrier P, et al. (2011) Prognostic factors influencing progression-free survival determined from a series of sporadic desmoid tumors: a wait-and-see policy according to tumor presentation. J Clin Oncol 29(26): 3553-3558.

15. Bonvalot S, Ternes N, Fiore M, Bitsakou G, Colombo C, et al. (2013) Spontaneous regression of primary abdominal wall desmoids: more common than previously thought. Ann Surg Oncol 20(13): 4096-4102.

16. Waddell WR, Kirsch WM (1991) Testolactone, sulindac, warfarin, and vitamin K1 for unresectable desmoid tumors. Am J Surg 161(4): 416421. 
17. Tsukada K, Church JM, Jagelman DG, Fazio VW, McGannon E, et al (1992) Noncytotoxic drug therapy for intra-abdominal desmoid tumor in patients with familial adenomatous polyposis. Dis Colon Rectum 35(1): 29-33.

18. Klein WA, Miller HH, Anderson M, DeCosse JJ (1987) The use of indomethacin, sulindac, and tamoxifen for the treatment of desmoid tumors associated with familial polyposis. Cancer 60(12): 2863-2864.

19. Dominguez-Malagon HR, Alfeiran-Ruiz A, Chavarria-Xicotencatl P, Duran-Hernandez MS (1992) Clinical and cellular effects of colchicine in fibromatosis. Cancer 69(10): 2478-2483.

20. Nishida Y, Tsukushi S, Shido Y, Urakawa H, Arai E, et al. (2012) Transition of treatment for patients with extra-abdominal desmoid tumors: nagoya university modality. Cancers (Basel) 4(1): 88-99.
21. Fiore M, Colombo C, Radaelli S, Callegaro D, Palassini E, et al. (2015) Hormonal manipulation with toremifene in sporadic desmoid-type fibromatosis. Eur J Cancer 51(18): 2800-2807.

22. Janinis J, Patriki M, Vini L, Aravantinos G, Whelan JS (2003) The pharmacological treatment of aggressive fibromatosis: a systematic review. Ann Oncol 14(2): 181-190.

23.Zlotecki RA, Scarborough MT, Morris CG, Berrey BH, Lind DS, et al. (2002) External beam radiotherapy for primary and adjuvant management of aggressive fibromatosis. Int J Radiat Oncol Biol Phys 54(1): 177-181.

24. Lakhani S, Ellis I, Schnitt S, Hoon Tan P, van der Vijver M (2012) WHO Classification of tumours of the breast. ( $4^{\text {th }}$ edn), Lyon, France.

\section{Your next submission with Juniper Publishers will reach you the below assets}

- Quality Editorial service

- Swift Peer Review

- Reprints availability

- E-prints Service

- Manuscript Podcast for convenient understanding

- Global attainment for your research

- Manuscript accessibility in different formats

( Pdf, E-pub, Full Text, Audio)

- Unceasing customer service

Track the below URL for one-step submission https://juniperpublishers.com/online-submission.php 